\title{
VALIDATION OF DOUBLE-PULSE 1572 NM INTEGRATED PATH DIFFERENTIAL ABSORPTION LIDAR MEASUREMENT OF CARBON DIOXIDE
}

\author{
Juan Du ${ }^{1,2}$,Jiqiao Liu ${ }^{1 *}$, Decang Bi ${ }^{1}$, Xiuhua $\mathrm{Ma}^{1}, \mathrm{Xia} \mathrm{Hou}^{1}$, Xiaolei Zhu ${ }^{1}$,Weibiao Chen ${ }^{1}$ \\ 1 Key Laboratory of Space Laser Communication and Detection Technology, Shanghai Institute of Optics \\ and Fine Mechanics, CAS, No.390 Qinghe Road, Jiading, Shanghai 201800, China
}

2 University of Chinese Academy of Sciences, Beijing 100049, China

*Email: liujiqiao@siom.ac.cn

\begin{abstract}
A ground-based double-pulse $1572 \mathrm{~nm}$ integrated path differential absorption (IPDA) lidar was developed for carbon dioxide $\left(\mathrm{CO}_{2}\right)$ column concentrations measurement. The lidar measured the $\mathrm{CO}_{2}$ concentrations continuously by receiving the scattered echo signal from a building about $1300 \mathrm{~m}$ away. The other two instruments of TDLAS and in-situ $\mathrm{CO}_{2}$ analyzer measured the $\mathrm{CO}_{2}$ concentrations on the same time. A $\mathrm{CO}_{2}$ concentration measurement of $430 \mathrm{ppm}$ with $1.637 \mathrm{ppm}$ standard error was achieved.
\end{abstract}

\section{INTRODUCTION}

$\mathrm{CO}_{2}$ is one of the main atmospheric greenhouse gases and plays an important role in global climate change. Global $\mathrm{CO}_{2}$ concentrations with high precision measurements are significant for understanding the carbon cycle and improving the climate forecast model. A more accurate and effective technique to measure global atmospheric $\mathrm{CO}_{2}$ concentrations has become strongly required. Differential absorption lidar (DIAL) technique is an effective method for trace gas concentrations measurement with high accuracy and sensitivity. In order to measure column $\mathrm{CO}_{2} \quad\left(\mathrm{XCO}_{2}\right)$ concentrations from space, the integrated path differential absorption (IPDA) lidar is proposed [1-3.] . Usually $1.57 \mu \mathrm{m}$ and $2 \mu \mathrm{m}$ wavelength laser sources are acted as the preferred transmitter for IPDA lidar to measure $\mathrm{XCO}_{2}$ [4-6.]. Although the laser frequency stability is stricter for $1.57 \mu \mathrm{m}$ than $2 \mu \mathrm{m}$ laser source, the $1.57 \mu \mathrm{m}$ lidar shows lower interference from water vapor and lower sensitivity from atmospheric temperature [7.]. In this paper, an IPDA lidar prototype system for
$\mathrm{CO}_{2}$ concentration measurement based on $1.57 \mu \mathrm{m}$ and some experiment results are presented. The optimized on-line and off-line wavelengths are $6361.2250 \mathrm{~cm}^{-1}$ and $6360.979 \mathrm{~cm}^{-1}$ respectively, which are shown in Figure 1. The lidar are compared with TDLAS and in-situ $\mathrm{CO}_{2}$ analyzer (Los Gatos) in measuring the $\mathrm{CO}_{2}$, and good agreements are shown.

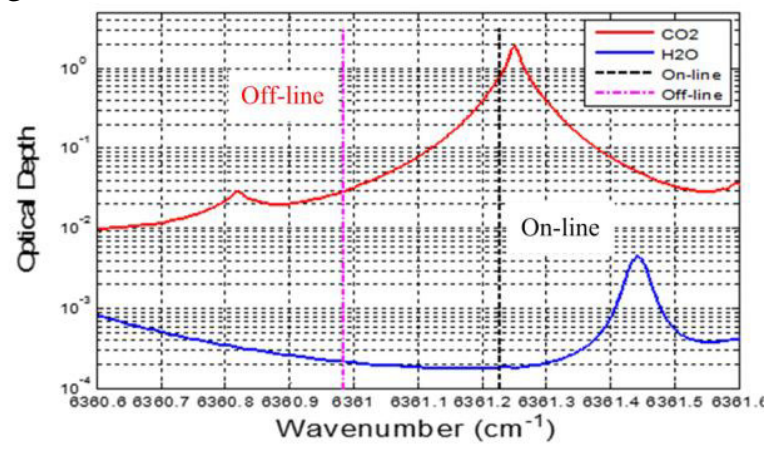

Figure 1 Operation wavelength of the IPDA lidar

\section{SYSTEM CONFIGURATION}

The block diagram of the IPDA lidar system is shown in Figure 2. This system consisted of the laser transmitter, the receiver, and the data acquisition and controller. The laser transmitter output $1572 \mathrm{~nm}$ and $1064 \mathrm{~nm}$ double-pulse lasers simultaneously. The double pulse's separation was $200 \mu \mathrm{s}$. The $1064 \mathrm{~nm}$ laser was used to measure range to hard target. The $1572 \mathrm{~nm}$ laser with on-line wavelength $6361.2250 \mathrm{~cm}^{-1}$ and offline wavelength $6360.979 \mathrm{~cm}^{-1}$ was used to measure $\mathrm{CO}_{2}$ concentrations. The $1572 \mathrm{~nm}$ laser was generated by the seeder injected optical parametric oscillator (OPO) method with single frequency $1064 \mathrm{~nm}$ laser acted as the pump laser pulse. The $1572 \mathrm{~nm}$ laser single pulse energy was about $1 \mathrm{~mJ}$ with $50 \mathrm{~Hz}$ repetition rate and $20 \mathrm{~ns}$ pulse duration. In the laser transmitter, part of 
$1572 \mathrm{~nm}$ pulsed laser was received by an integrating sphere and detected by an InGaAs PIN photodiode. It was sampled and acted as the transmitting laser energy calibration reference. The receiver was composed of a $200 \mathrm{~mm}$ Schmidt-Cassegrain telescope, an $1572 \mathrm{~nm}$ detector channel and an $1064 \mathrm{~nm}$ detector channel. The $1572 \mathrm{~nm}$ detector channel signal was amplified by a $2 \mathrm{MHz}$ bandwidth amplifier. Then the signal was sampled by an $100 \mathrm{M} / \mathrm{s}$ AD card in the data acquisition and controller unit. The specifications of the system are summarized in the table 1.

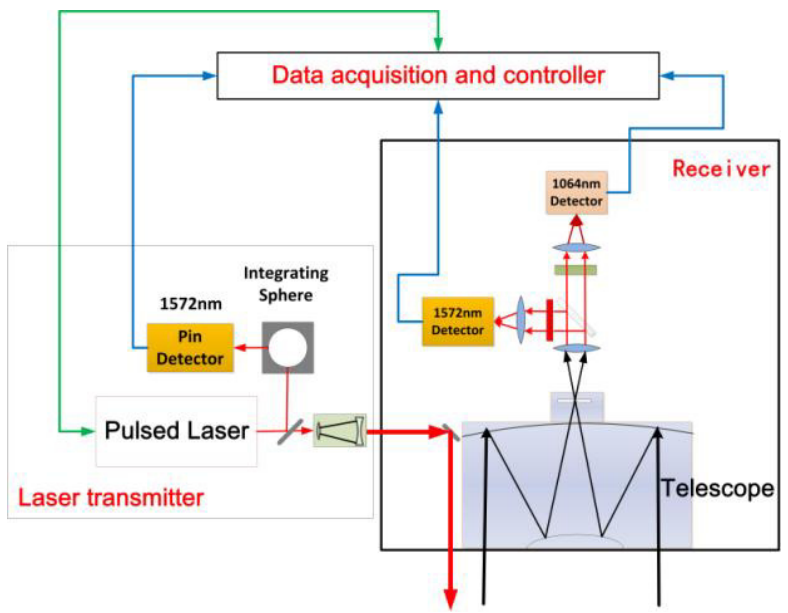

Figure 2 Block diagrams of the IPDA lidar system

Table1 Specifications of the lidar system

\begin{tabular}{|l|l|}
\hline Parameters & value \\
\hline Wavelength & $1572 \mathrm{~nm} / 1064 \mathrm{~nm}$ \\
\hline Pulse energy & $\begin{array}{l}1 \mathrm{~mJ} @ 1572 \mathrm{~nm} \\
5 \mathrm{~mJ} @ 1064 \mathrm{~nm}\end{array}$ \\
\hline Pulse width & $20 \mathrm{~ns}$ \\
\hline Frequency stability & $0.3 \mathrm{MHz}$ \\
\hline Pulse repetition rate & $50 \mathrm{~Hz}$ (double pulse) \\
\hline Beam divergence & $0.2 \mathrm{mrad}$ \\
\hline Telescope & $\Phi 200 \mathrm{~mm}$ \\
\hline FOV & $0.5 \mathrm{mrad}$ \\
\hline Detector & $\begin{array}{l}\text { Thorlabs PDA20CS-EC PIN } \\
\text { Licel InGaAs APD module } \\
\text { Licel Si APD module }\end{array}$ \\
\hline AD & $100 \mathrm{M} / \mathrm{s}, 14 b i t$, NI PCI5122 \\
\hline
\end{tabular}

\section{RESULTS}

\subsection{Retrieval method}

The $\mathrm{CO}_{2}$ differential absorption optical depth (DAOD) was calculated from the following expression:

$$
D A O D=\int_{0}^{R} N_{C O_{2}}(r) \Delta \sigma(r) d r=\frac{1}{2} \ln \frac{P_{o f f}}{P_{o n}} \frac{P_{o n 0}}{P_{o f f} 0},
$$

Where $\Delta \sigma(r)=\sigma_{\text {on }}-\sigma_{\text {off }}$ was the differential absorption section, $P_{o n}$ and $P_{\text {off }}$ were the echo signals from IPDA double pulses, $P_{o n 0}$ and $P_{o f f} 0$ were the transmitting energy reference signals. Usually, multiple pulses were averaged to calculate DAOD with high accuracy.

The column $\mathrm{CO}_{2}$ concentration $\left(\mathrm{XCO}_{2}\right)$ could be calculated from the DAOD and the integrated weighting function WF, and was expressed as:

$$
\begin{aligned}
& X C O_{2}==\frac{D A O D}{\int_{P_{r_{\text {aro }}}}^{p_{\text {art }}} W F(p, T) d p}, \\
& W F(P, T)=\frac{\Delta \sigma_{C O_{2}}(P, T)^{*} N_{\text {air }},}{1+\rho_{H_{2} O}}, \\
& N_{\text {air }}=\frac{P \cdot N A}{R T} .
\end{aligned}
$$

Where the weighting function $W F(p, T)$ was related to operational on-line and off-line wavelengths, and atmospheric parameters such as pressure and temperature and water vapor concentrations.

The $\mathrm{XCO}_{2}$ relative random error (RRE) was expressed in the following as:

$$
R R E=\frac{\Delta X C O_{2}}{X_{2}}=\frac{\Delta D A O D}{D A O D}=\frac{1}{2 \cdot D A O D \cdot} \frac{1}{S N R},
$$

Where the SNR was the signal to noise ratio of total echo and energy monitor reference signals. So when the DAOD kept constant, RRE was only decided by the SNR. For lower RRE, higher SNR was required.

\subsection{Experiments}

Ground validation experiments were carried out for the IPDA lidar system compared with TDLAS and in-situ $\mathrm{CO}_{2}$ analyzer instruments. Atmosphere pressure, temperature and water 
vapor concentration were recorded by the Davis weather station.

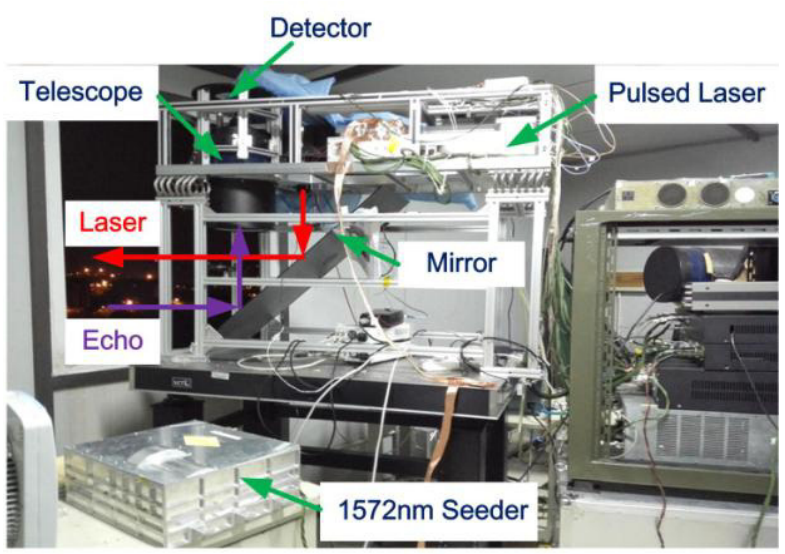

Figure 3 The IPDA lidar prototype

Figure 3 shows the IPDA lidar prototype. The transmitting laser beam was rotated 90 degrees by a mirror, and then passed the window in the lab to the atmosphere. The lab was on the top of fivestory building. The lidar would receive the echo signal scattered by a building about $1300 \mathrm{~m}$ away. Then the $\mathrm{XCO}_{2}$ in horizontal plane could be measured by the lidar. On the same time, the insitu $\mathrm{CO}_{2}$ analyzer could measure the $\mathrm{CO}_{2}$ concentrations outside the lab with accuracy less than $0.3 \mathrm{ppm}$. The TDLAS instrument also was used to make comparisons. But it was different from the lidar and the path length was only about $120 \mathrm{~m}$. Because the energy of its light was not enough to measure long-distance $\mathrm{CO}_{2}$.

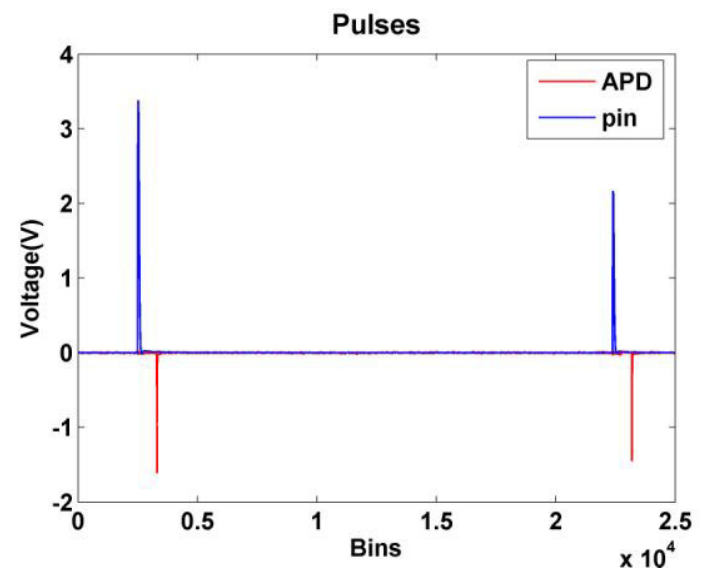

Figure 4 The lidar acquired double pulse echo and energy monitor signals

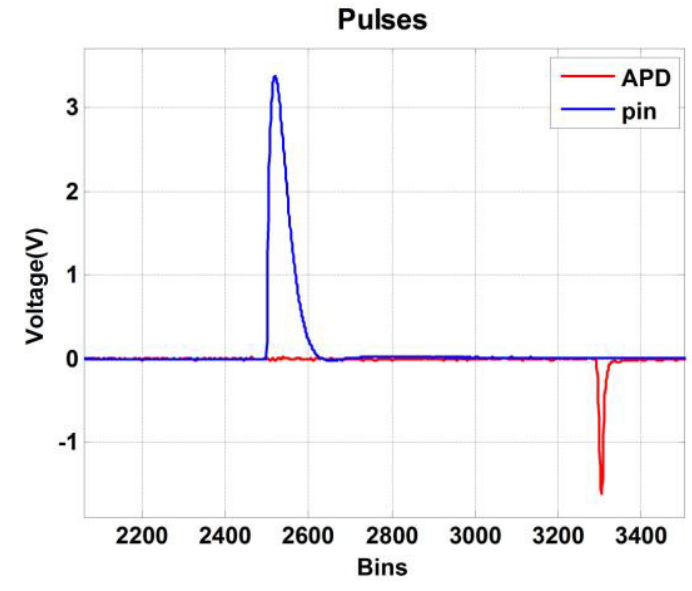

Figure 5 Single pulse echo and energy monitor signals waveform

The lidar acquired double pulse echo and energy monitor signals, shown in Figure 4. Energy monitor signals were received by a PIN detector with positive voltage. And the scattered echo signals were received by an APD detector with negative voltage output. The single pulse echo and energy monitor signals waveform are shown in Figure 5.

From the measured atmospheric parameters and calculated weighting function and background $\mathrm{XCO}_{2}$ of about $400 \mathrm{ppm}$, we can calculate the theoretical value of DAOD which was 0.087 . Online and off-line normalized single echo signals are presented in Figure 6. When 4000 pulses averaged, the ratio of on-line and off-line normalized echo signal which is also the ratio in the $\log$ term of equation (1), shown in Figure 7. Then we got the DAOD, as shown in Figure 8. The mean DAOD was 0.0877 , which agree with the theoretical DAOD.

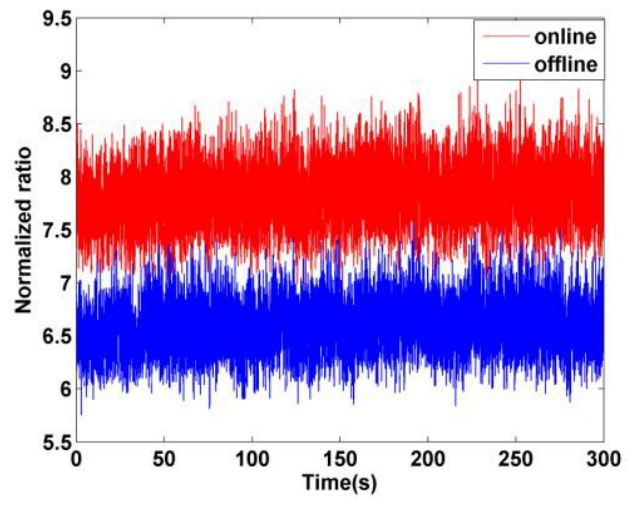

Figure 6 On-line and off-line normalized echo signal 


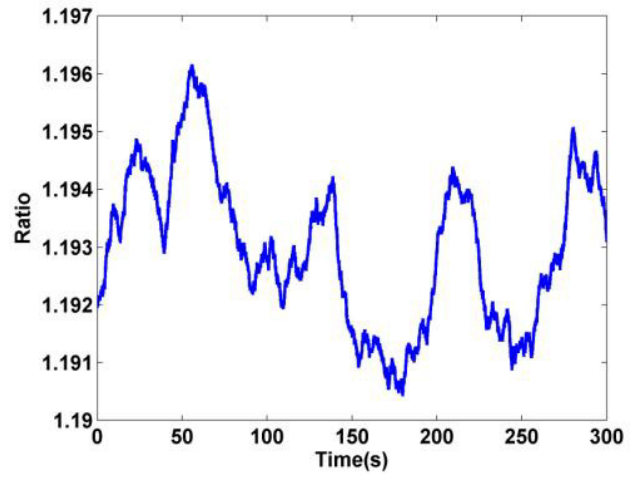

Figure 7 Ratio of on-line and off-line normalized echo signal

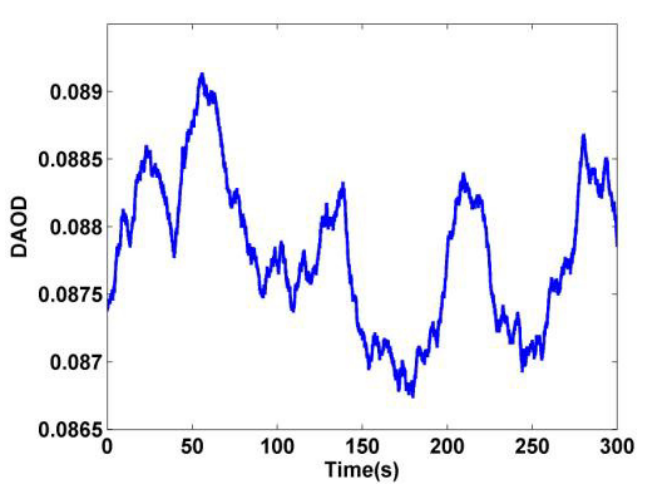

Figure 8 Calculated DAOD

The IPDA lidar retrieved $\mathrm{XCO}_{2}$ compared with Los Gatos in-situ analyzer measured $\mathrm{CO}_{2}$ concentration is shown in Figure 9. The mean $\mathrm{XCO}_{2}$ from lidar is about $430 \mathrm{ppm}$ with $1.637 \mathrm{ppm}$ standard error. Both lidar and in-situ analyzer measured data agree well. On another day, the IPDA lidar retrieved $\mathrm{XCO}_{2}$ is also compared with TDLAS, presented in Figure 10. The TDLAS path length was about $120 \mathrm{~m}$ and the cube corner retro-reflector target azimuth was different from the lidar scattered building wall. But both showed good correlation.

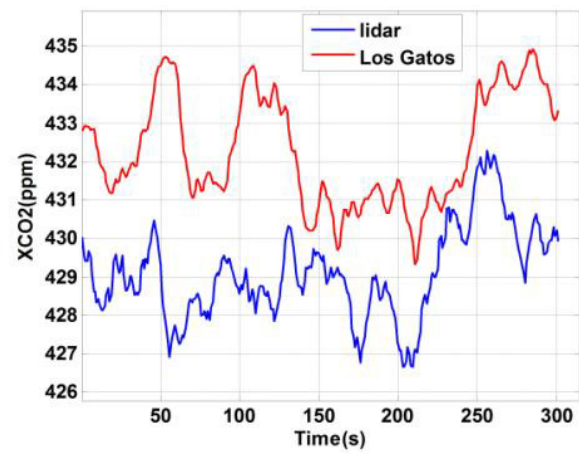

Figure 9 Comparison of XCO2 measured by lidar and Los Gatos in-situ analyzer

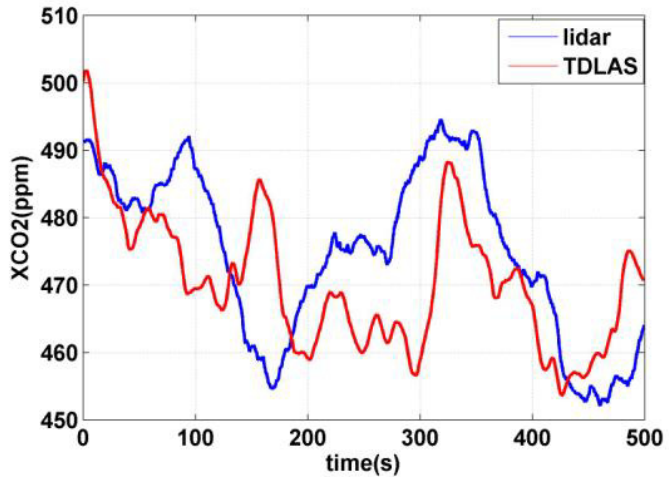

Figure 10 Comparison of $\mathrm{XCO}_{2}$ measured by lidar and TDLAS

\section{CONCLUSIONS}

A ground-based double-pulse $1572 \mathrm{~nm}$ integrated path differential absorption (IPDA) lidar was developed for carbon dioxide $\left(\mathrm{CO}_{2}\right)$ column concentrations measurement. The lidar was compared with TDLAS and in-situ $\mathrm{CO}_{2}$ analyzer to measure the column $\mathrm{CO}_{2}$ concentrations. Good agreement was shown. When 4000 pulses averaged, the mean $\mathrm{XCO}_{2}$ of $1300 \mathrm{~m}$ path length from lidar was about $430 \mathrm{ppm}$ with $1.637 \mathrm{ppm}$ standard error. This lidar will be upgraded soon for $\mathrm{XCO}_{2}$ measurement in future airborne platform.

\section{ACKNOWLEDGEMENT}

This work is supported by Chinese atmosphere environment monitoring satellite project program.

\section{REFERENCES}

[1] ASCENDS (Active Sensing of CO2 Emissions over Nights, Days, and Seasons), http://decadal.gsfc.nasa.gov/ASCENDS.html.

[2] J. Caron, Y. Durand, J.-L. Bezy, and R. Meynart. 2009: Performance modeling for A-SCOPE, a space borne lidar measuring atmospheric $\mathrm{CO} 2$. Proc. SPIE, 7479: 74790E.

[3] Ehret, G. und Kiemle, C. und Wirth, M. und Amediek, A. und Fix, A. und Houwrling, S. ,2008: Space-borne remote sensing of $\mathrm{CO} 2, \mathrm{CH} 4$, and $\mathrm{N} 2 \mathrm{O}$ by integrated path differential absorption lidar: a sensitivity analysis. Applied Physics B, 90, p.593-608

[4]Amediek, A. Fix, M. Wirth, and G. Ehret, 2008: Development of an OPO system at $1.57 \mu \mathrm{m}$ for integrated path DIAL measurement of atmospheric carbon dioxide, Appl. Phys. B ,92, 295-302 
[5]G. Wagner and D. Plusquellic, 2016: Ground-based, integrated path differential absorption LIDAR measurement of $\mathrm{CO} 2, \mathrm{CH} 4$, and $\mathrm{H} 2 \mathrm{O}$ near $1.6 \mu \mathrm{m}$, Appl. Opt. 55, 6292-6310

[6]Tamer F. Refaat, Upendra N. Singh, Jirong Yu, Mulugeta Petros, Ruben Remus, and Syed Ismail, 2016: Double-pulse $2-\mu \mathrm{m}$ integrated path differential absorption lidar airborne validation for atmospheric carbon dioxide measurement, Appl. Opt. 55, 4232-4246

[7] Jérôme Caron and Yannig Durand, 2009: Operating wavelengths optimization for a spaceborne lidar measuring atmospheric CO2, Appl. Opt.48, 5413-5422 (2009) 